\title{
ANALISIS PENERAPAN ECONOMIC ORDER QUANTITY (EOQ) DI PABRIK GULA MADUKISMO BANTUL
}

\author{
Risa Rahmawati*, Endang Siti Rahayu dan Susi Wuri Ani \\ Program Studi Agribisnis Fakultas Pertanian, Universitas Sebelas Maret \\ *Corresponding author: rahmarisa@student.uns.ac.id
}

\begin{abstract}
The purpose of this research to analyze the result of Economic Order Quantity in Madukismo Sugar Manufacture during the year of 2013-2015. The basic method used in this research was analytical, descriptive with case study technique. Data analysis used Economic Order Quantity (EOQ). The results of the study showed that during 2013-2015 the order quantity according to Madukismo Sugar Manufacture policy was 29.377 Quintal with the frequency of ordering 192 times, 30.328.46 Quintal with the frequency of ordering 168 times, and 31.883,06 Quintal with the frequency of ordering 142 times, sequentially. Whereas the result of Economic Order Quantity (EOQ) calculation during 20132015 where 52,916.47 Quintal with the frequency of ordering 107 times, 45,980.57 Quintal with a frequency 111 times, and 49,135.20 Quintal with a frequency 92 times, consecutively. The result of Economic Order Quantity calculation to intent filled up the needs of sugar cane and to maintain the sustainability of the production process. The effort to provide Economic Order Quantity of sugarcane,Madukismo Sugar Manufacture managed for expanding of sugarcane planting area. So that, Madukismo Sugar Manufacture could run the production process properly and sustainability.
\end{abstract}

Keywords: Economic order quantity; Frequency; Order; Sugarcane; Quantity

Cite this as: Rahmawati, R., Rahayu, E., \& Ani, S. 2017. Analisis Penerapan Economic Order Quantity (EOQ) di Pabrik Gula Madukismo Bantul. Caraka Tani: Journal of Sustainable Agriculture. 32(2), 126-131. doi: http://dx.doi.org/10.20961/carakatani.v32i2.15120

\section{PENDAHULUAN}

Setiap perusahaan memerlukan bahan baku dalam melangsungkan kegiatan produksi. Menurut Andari (2016), perusahaan yang memproduksi barang untuk memperoleh keuntungan memerlukan manajemen bahan baku yang baik karena bahan baku merupakan faktor penting dalam proses produksi. Pengelolaan bahan baku sangat penting untuk keseluruhan kinerja dari setiap kepentingan manufaktur (Akindipe, 2014). Permasalahan yang sering dialami sebuah perusahaan adalah pengadaan bahan baku yang terkadang tidak sesuai dengan kebutuhan perusahaan terutama dari segi kuantitas. Beberapa perusahaan bahkan sering mengalami kekurangan bahan baku produksi yang mengakibatkan proses produksi tidak optimal.

Pabrik gula (PG) Madukismo merupakan salah satu perusahaan di bidang agribisnis yang menghasilkan gula sebagai produk utama. Gula merupakan salah satu komoditas strategis yang dibutuhkan masyarakat (Kementerian Pertanian, 2015). Kedudukan gula sebagai bahan pemanis utama di Indonesia belum dapat digantikan oleh bahan pemanis lain yang digunakan baik oleh rumah tangga maupun industri makanan dan minuman (Ernawati dan Erma, 2013). Gula memiliki beberapa jenis antara lain gula kristal, gula aren, gula palem dan gula kelapa (Ulfah, 2015). Sedangkan gula yang dihasilkan PG Madukismo adalah gula kristal.

PG Madukismo juga sering mengalami kekurangan bahan baku dalam proses produksi karena pasokan bahan baku mengalami keterlambatan. Hal tersebut disebabkan PG Madukismo melaksanakan operasional perusahaan 24 jam selama musim giling, sehingga bahan baku merupakan komponen utama untuk keberlangsungan proses produksi yang perlu diperhitungkan dengan tepat. 
Tabel 1. Target dan Realisasi Ketersediaan Bahan Baku Tebu PG Madukismo tahun 2011 - 2015

\begin{tabular}{lllccccc}
\hline No. & \multicolumn{2}{c}{ Uraian } & $\mathbf{2 0 1 1}$ & $\mathbf{2 0 1 2}$ & $\mathbf{2 0 1 3}$ & $\mathbf{2 0 1 4}$ & $\mathbf{2 0 1 5}$ \\
\hline \multirow{2}{*}{1.} & Kapasitas Giling & Terpasang & 35.000 & 35.000 & 35.000 & 35.000 & 35.000 \\
& (Ku/Hari) & Realisasi & 32.924 & 33.005 & 31.168 & 32.161 & 32.791 \\
2. & Tebu & Target & 5.250 .000 & 5.350 .000 & 5.450 .000 & 5.500 .000 & 5.000 .000 \\
& $(\mathrm{Ku})$ & Realisasi & 4.152 .394 & 5.164 .429 & 5.640 .480 & 5.095 .214 & 4.520 .294 \\
\hline
\end{tabular}

Sumber: Data Sekunder PG Madukismo

Tabel 1 menunjukkan bahwa realisasi giling tebu per hari dalam satu periode giling masih kurang dari target kapasitas giling yang ditetapkan oleh PG Madukismo yakni sebesar 35.000 $\mathrm{Ku} / \mathrm{Hari}$. Hal tersebut karena realisasi bahan baku yang disediakan PG Madukismo seringkali belum memenuhi target yang ditentukan oleh perusahaan.

Kekurangan bahan baku produksi mengakibatkan PG Madukismo harus meninjau ulang kapasitas giling yang berarti proses produksi mengalami under capacity dari kapasitas giling yang telah ditargetkan sebelumnya. Selain itu, jika pengendalian bahan baku tidak diperhitungkan dengan baik, memungkinkan terjadinya stock out atau kehabisan bahan baku. Stock out akan berakibat pada proses giling terhenti sehingga target produksi tidak dapat dicapai. Permasalahan tersebut mengakibatkan biaya produksi semakin tinggi (boros). Target produksi pun tidak dapat terealisasi serta keberlanjutan proses produksi terhambat.

Salah satu kegiatan produksi yang dapat dilakukan untuk meminimalisasi permasalahan tersebut adalah dengan penentuan Economic Order Quantity bahan baku yang dibutuhkan perusahaan. Penerapan Economic Order Quantity bertujuan untuk memastikan persediaan bahan baku telah ditentukan seefisien mungkin dan sesuai dengan kebijakan perusahaan (Fadlallh, 2015). Bahan baku utama PG Madukismo adalah tebu.

Menurut Rizaldi (2004), tebu merupakan tanaman semusim yang membutuhkan waktu sekitar 8-14 bulan untuk bisa ditebang. Tebu dapat digunakan sebagai bahan baku produksi gula. Tebu juga termasuk komoditi yang tidak memiliki daya tahan lama. Berdasarkan penelitian Yolanda (2012), tebu yang telah ditebang cepat mengalami penyusutan dan penurunan kualitas jika setelah 36 jam tidak segera dilakukan pemrosesan. Hal tersebut berpengaruh terhadap penurunan produksi gula yang dihasilkan. Oleh karena itu, PG Madukismo perlu mempertimbangkan pemesanan bahan baku dengan baik, sehingga proses produksi dapat berjalan lancar dan tebu yang diproses sebagai bahan baku masih dalam standar kualitas yang ditetapkan, yaitu tebu BSM (Bersih, Segar, Manis) serta memiliki kandungan rendemen 6-8 \%. Penentuan jumlah pemesanan bahan baku di PG Madukismo dapat dilakukan dengan penerapan metode Economic Order Quantity (EOQ), sehingga keberlanjutan proses produksi dapat dipertahankan.

\section{METODE PENELITIAN}

Penelitian ini dilakukan pada bulan FebruariMaret 2017 dengan metode dasar yang digunakan dalam penelitian ini adalah deskriptif analitis dan teknik pelaksanaan dalam penelitian ini adalah studi kasus. Lokasi penelitian ini adalah Pabrik Gula Madukismo yang beralamat di Kasihan, Bantul, Yogyakarta dipilih dengan pertimbangan PG Madukismo merupakan satu-satunya pabrik gula yang masih aktif dalam memproduksi gula di Yogyakarta. Selain itu, PG Madukismo belum menerapkan metode EOQ dalam penentuan jumlah pemesanan bahan baku.

Menurut teori Baroto (2002), model persediaan diklasifikasikan menjadi Metode Q dan Metode P. Metode Q terdiri dari banyak model salah satunya Economic Order Quantity (EOQ). Alat analisis yang digunakan dalam penelitian ini yakni dengan Economic Order Quantity.

Economic Order Quantity (EOQ) dihitung dengan rumus

Keterangan:

$$
\mathrm{EOQ}=\sqrt{\frac{2 D S}{H}}
$$

EOQ : jumlah pemesanan ekonomis,

$\mathrm{S} \quad$ : biaya setiap kali pesan,

D : jumlah kebutuhan tebu dalam satu periode produksi,

$\mathrm{H} \quad$ : biaya penyimpanan dinyatakan dalam presentase dari persediaan rata-rata bahan baku. 
Sedangkan frekuensi pemesanan yang dapat diperoleh dengan rumus

$$
\mathrm{I}=\frac{D}{E O Q}
$$

Keterangan:

I : frekuensi pemesanan optimal

EOQ : jumlah pemesanan ekonomis,

D : jumlah penggunaan bahan baku dalam satu periode per unit (Heizer dan Barry, 2008).

\section{HASIL DAN PEMBAHASAN}

Pabrik Gula Madukismo merupakan satusatunya Pabrik Gula di Provinsi Daerah Istimewa Yogyakarta yang mengemban tugas untuk mensukseskan program pengadaan pangan nasional, khususnya gula pasir. PG Madukismo juga sebagai perusahaan padat karya yang mampu menampung banyak tenaga kerja di Provinsi Daerah Istimewa Yogyakarta.
Pabrik Gula Madukismo terletak di Desa Padokan, Kelurahan Tirtonirmolo, Kecamatan Kasihan, Kabupaten Bantul, Provinsi Daerah Istimewa Yogyakarta. Tepatnya berada $\pm 5 \mathrm{~km}$ di sebelah Barat Daya Kota Yogyakarta dengan ketinggian 14 meter di atas permukaan laut. Pabrik Gula Madukismo dibangun di atas lokasi bangunan Pabrik Gula Padokan, satu dari 17 Pabrik Gula yang pernah dibangun oleh Pemerintahan Belanda di Daerah Istimewa Yogyakarta, tetapi dibumi hanguskan pada masa Pemerintahan Jepang.

Penyediaan tebu di PG Madukismo berasal dari pasokan tebu petani mitra dan petani mandiri. Tebu yang dipasok oleh petani tersebut dibeli oleh PG Madukismo sesuai kontrak yang telah disepakati. Penyediaan tebu di PG Madukismo dilakukan setiap hari giling selama musim giling berlangsung. Oleh karena itu, frekuensi pemesanan tebu sama dengan jumlah hari giling yang dilakukan. Musim giling hanya berlangsung sekitar 4-7 bulan.

Tabel 2. RKAP dan Realisasi Hari Giling PG Madukismo tahun 2010 - 2015

\begin{tabular}{lcccccc}
\hline Hari Giling & $\mathbf{2 0 1 0}$ & $\mathbf{2 0 1 1}$ & $\mathbf{2 0 1 2}$ & $\mathbf{2 0 1 3}$ & $\mathbf{2 0 1 4}$ & $\mathbf{2 0 1 5}$ \\
\hline RKAP (hari) & 168 & 178 & 159 & 160 & 166 & 166 \\
Realisasi (hari) & 199 & 130 & 165 & 192 & 168 & 142 \\
\hline
\end{tabular}

Sumber: Data Sekunder PG Madukismo

* Keterangan: RKAP (Rencana Kerja dan Anggaran Perusahaan)

Tabel 2 menunjukkan bahwa lama periode produksi di PG Madukismo fluktuatif. Jika dilihat dari tahun ke tahun, rata-rata waktu giling tebu di PG Madukismo berkisar antara 4 hingga 7 bulan. Perbedaan lama periode giling di PG Madukismo dipengaruhi oleh kinerja perusahaan dan jumlah tebu yang dapat digiling setiap hari.

Proses produksi berlangsung 24 jam setiap hari selama musim giling. Musim giling tebu di PG Madukismo biasanya berlangsung mulai dari bulan Mei hingga September, namun dapat berlanjut sampai bulan Desember. Hal tersebut tergantung pada ketersediaan tebu di lahan yang belum ditebang. Tebu di lahan-lahan petani telah dipersiapkan PG Madukismo dari sebelum melangsungkan proses giling, sehingga PG Madukismo hanya perlu memperhitungkan jumlah tebu yang akan ditebang per harinya. Oleh karena itu, jika jumlah tebu yang ditebang per hari kurang dari target, maka akan semakin lama hari giling tebu di PG Madukismo, karena ketersediaan tebu di lahan masih banyak. Namun penentuan jumlah tebu yang ditebang per hari memungkinkan terjadinya kekurangan tebu yang akan digiling (under capacity) sehingga dapat menyebabkan proses produksi yang kurang efisien. Proses produksi yang kurang efisien tersebut karena PG Madukismo akan mengalami kerugian waktu, tenaga kerja, maupun target produksi gula tidak tercapai jika harus menyetel ulang kapasitas produksi yang telah ditetapkan akibat terjadinya under capacity pasokan tebu per hari.

Kapasitas giling yang ditetapkan oleh PG Madukismo sebanyak 3.500 TCD (Ton Cane per Day). Sebelum tebu digiling, tebu yang sampai di pabrik setelah pengangkutan dari lahan akan dilakukan penyimpanan sementara yang membentuk antrian tebu untuk digiling sedikit demi sedikit. Penyimpanan tebu sementara yaitu menggunakan lori yang digerakkan oleh lokomotif. Kapasitas maksimal penyimpanan sementara tebu di PG Madukismo sekitar 55.000 kuintal. Dikatakan penyimpanan sementara 
karena pada prinsipnya tebu tidak disimpan di gudang penyimpanan dalam waktu yang lama, namun hanya untuk sementara waktu sebagai stok bahan baku agar proses produksi dapat terus berlangsung. Hal tersebut bertujuan untuk menjaga kualitas tebu dan agar proses produksi dapat berlangsung secara kontinyu. Waktu penyimpanan tebu maksimal di PG Madukismo untuk mendapatkan kualitas tebu yang masih baik yaitu 36 jam setelah tebu ditebang.

Oleh karena itu, agar tebu yang diproses untuk pembuatan gula kristal masih dalam standar kualitas yang ditentukan PG Madukismo, maka perlu perencanaan pengadaan persediaan tebu yang tepat. Hal tersebut dapat dilakukan dengan perhitungan analisis Economic Order Quantity (EOQ) agar PG Madukismo dapat memperoleh keuntungan paling optimal.

\section{Economic Order Quantity}

Berdasarkan hasil perhitungan Economic Order Quantity (EOQ) dengan kebijakan perusahaan, terdapat selisih jumlah dan frekuensi pemesanan bahan baku di PG Madukismo dengan hasil metode EOQ pada Tabel 3.

Tabel 3. Selisih Jumlah Pemesanan Tebu antara Kebijakan PG Madukismo dengan Metode EOQ Tahun 2013-2015

\begin{tabular}{lcccccc}
\hline \multirow{2}{*}{ Tahun } & \multicolumn{2}{c}{ Kebijakan Perusahaan } & \multicolumn{2}{c}{ Metode EOQ } & \multicolumn{2}{c}{ Selisih } \\
& Q (Kuintal) & Frek (kali) & Q (Kuintal) & Frek (kali) & Q (Kuintal) & Frek (kali) \\
\hline 2013 & $29.377,46$ & 192 & $52.916,47$ & 107 & $23.539,01$ & 85 \\
2014 & $30.328,46$ & 168 & $45.980,57$ & 111 & $15.651,93$ & 57 \\
2015 & $31.833,06$ & 142 & $49.135,20$ & 92 & $17.302,14$ & 50 \\
\hline Rata-rata & $30.512,99$ & 167 & $49.344,10$ & 103 & $18.831,03$ & 64 \\
\hline
\end{tabular}

Sumber: Analisis Data Sekunder, 2017

Tabel 3 menunjukan selisih hasil perhitungan jumlah pemesanan tebu berdasarkan kebijakan PG Madukismo dengan hasil perhitungan metode EOQ. Selisih jumlah pemesanan tebu dari tahun 2013-2015 secara berturut-turut yaitu 23.539,01 kuintal, 15.651,93 kuintal dan 17.302,14 kuintal dengan hasil perhitungan menggunakan metode EOQ menghasilkan jumlah pemesanan tebu lebih banyak. Namun, frekuensi pemesanan dengan metode EOQ lebih sedikit dibandingkan kebijakan PG Madukismo. Selisih frekuensi pemesanan tahun 2013-2015 secara berturut-turut yakni 85,57 dan 50 kali pemesanan.

Rata-rata jumlah pemesanan tebu berdasarkan kebijakan PG Madukismo selama ini masih kurang dari kapasitas giling yang ditetapkan, yakni sebesar 35.000 kuintal per hari. Hal itu disebabkan karena PG Madukismo tidak menentukan jumlah stok pengaman tebu minimal untuk cadangan bahan baku proses produksi keesokan pagi, ketika pasokan tebu belum sampai di pabrik. PG Madukismo hanya menyisakan sebagian jumlah pemesanan tanpa menentukan target tertentu yang harus dipenuhi, sehingga untuk proses produksi hari berikutnya sering terjadi under capacity terutama pada pagi hari ketika pasokan tebu belum datang.
Sedangkan hasil analisis Economic Order Quantity (EOQ) menghasilkan jumlah lebih banyak dengan frekuensi lebih sedikit yang bertujuan untuk menghemat biaya pemesanan. Selain itu bertujuan agar PG Madukismo dapat memenuhi kapasitas giling yang ditetapkan per hari dan menjaga keberlanjutan proses produksi. Jumlah pemesanan yang lebih besar dari kapasitas giling PG Madukismo juga ditujukan agar tidak terjadi kekurangan tebu yang menyebabkan under capacity atau bahkan proses produksi terhenti karena Stocks Out.

Berdasarkan hasil penelitian, PG Madukismo sering mengalami under capacity ketika produksi pagi hari karena pasokan tebu pada hari itu belum sampai di pabrik. Hal tersebut karena proses penebangan tebu baru dimulai pada pagi hari sekitar pukul 06.00, sehingga baru diangkut ketika memenuhi kapasitas truk pengangkut dan sampai di pabrik sekitar pukul 09.00 untuk lahan tebu terdekat dengan lokasi pabrik. Selain itu, sering terjadi keterlambatan pasokan tebu ke pabrik yang mengakibatkan kekurangan stok tebu atau bahkan kehabisan stok tebu. Keterlambatan pasokan tebu di PG Madukismo disebabkan karena berbagai kendala yang tidak dapat dipastikan, sebagai contoh perbaikan jalan yang menyebabkan kemacetan, sehingga pengangkutan tebu 
memerlukan waktu lebih lama dari seharusnya. Keterlambatan pasokan tebu tersebut dapat mengakibatkan ketersediaan bahan baku produksi (tebu) di bawah kapasitas giling yang ditentukan (under capacity) atau bahkan kehabisan bahan baku (stocks out).

Kekurangan stok tebu (under capacity) adalah kondisi dimana jumlah tebu yang akan digiling (dalam penyimpanan sementara) tidak dapat memenuhi kapasitas giling pabrik. Jika PG Madukismo mengalami under capacity, proses produksi masih dapat berlangsung, namun harus melakukan peninjauan ulang kapasitas giling, sehingga proses produksi tertunda yang akan mengakibatkan target produksi sulit dicapai. Selain itu, PG Madukismo juga harus mengeluarkan biaya tambahan karena peninjauan ulang kapasitas giling. Sedangkan kehabisan stok (stocks out) adalah kondisi dimana jumlah tebu yang akan digiling jauh dari kapasitas giling pabrik. Stocks out akan berdampak pada berhentinya proses giling. Jika proses giling tetap berlangsung justru akan merugikan pihak perusahaan karena biaya produksi yang dikeluarkan jauh lebih besar dibandingkan output gula yang dihasilkan. Stocks out juga mengakibatkan target produksi sulit dicapai. Di samping itu, PG Madukismo akan mengalami kerugian pada biaya untuk menghidupkan ulang mesin produksi dan biaya tetap yang dikeluarkan, seperti biaya tenaga kerja. Oleh karena itu, sebaiknya PG Madukismo melakukan evaluasi dalam memperhitungkan persediaan pasokan tebu per hari. Metode Economic Order Quantity (EOQ) dapat menjadi salah satu alternatif alat untuk memperhitungkan jumlah pemesanan yang ekonomis bagi PG Madukismo. Selain itu, metode Economic Order Quantity (EOQ) memberikan keuntungan bagi PG Madukismo dengan cara mengantisipasi kekurangan bahan baku maupun kehabisan bahan baku, serta target produksi dapat dicapai dengan penentuan jumlah bahan baku melebihi kapasitas giling di pabrik.

Kelebihan jumlah stok tebu atau sisa tebu dari Economic Order Quantity (EOQ) dapat dijadikan stok pengaman untuk proses giling hari berikutnya. Namun, stok tebu juga harus dipertimbangkan dengan tepat agar tidak melebihi kebutuhan PG Madukismo. Tebu yang tersisa terlalu banyak dari hari giling sebelumnya, mengakibatkan biaya penyimpanan yang dikeluarkan semakin tinggi dan tebu mengalami penurunan kualitas. Penurunan kualitas tebu berakibat pada penurunan rendemen tebu dan kadar sukrosa tebu jika lebih dari 36 jam setelah penebangan belum digiling (Oktavia, 2014). Hal tersebut mengakibatkan hasil produksi gula yang diperoleh di bawah target yang diharapkan, karena gula yang dihasilkan salah satunya bergantung pada kandungan rendemen tebu. Oleh sebab itu, stok pengaman tebu yang terlalu banyak juga merugikan PG Madukismo karena semakin banyak biaya penyimpanan tebu yang dikeluarkan dan penurunan hasil produksi gula yang didapatkan karena penurunan rendemen tebu. Dengan perhitungan Economic Order Quantity (EOQ), diperoleh stok pengaman yang dapat meminimalkan jumlah penambahan biaya penyimpanan dan biaya kehabisan bahan baku (Heizer dan Barry, 2010).

Untuk memenuhi kebutuhan tebu serta mempertahankan keberlanjutan proses produksi, PG Madukismo selalu mengupayakan perluasan areal tanam tebu. Perluasan areal tanam tebu diharapkan dapat meningkatkan produksi tebu sebagai bahan baku produksi gula. Tabel 4 menyajikan perkembangan areal tanam tebu PG Madukismo tahun 2010-2015.

Tabel 4. Perkembangan Areal Tanam Tebu PG Madukismo Tahun 2010-2015

\begin{tabular}{lcccccc}
\hline Tahun & $\mathbf{2 0 1 0}$ & $\mathbf{2 0 1 1}$ & $\mathbf{2 0 1 2}$ & $\mathbf{2 0 1 3}$ & $\mathbf{2 0 1 4}$ & $\mathbf{2 0 1 5}$ \\
\hline Areal $(\mathrm{Ha})$ & $6.597,92$ & $6.681,75$ & $6.999,62$ & $7.351,67$ & $7.374,76$ & $7.273,67$ \\
\hline
\end{tabular}

Sumber: Data Sekunder PG Madukismo

Berdasarkan Tabel 4 dapat diketahui bahwa PG Madukismo berhasil meningkatkan luas areal tanam dari tahun 2010 hingga tahun 2014, namun mengalami penurunan pada tahun 2015. Hal tersebut karena adanya alih fungsi lahan di beberapa daerah. Namun PG Madukismo selalu berupaya mencari areal tanam tebu baru pada lahan potensial milik petani di beberapa wilayah
Yogyakarta dan sekitarnya untuk mempertahankan pasokan tebu, sehingga PG Madukismo dapat menjaga keberlanjutan dan keberlangsungan proses produksi gula yang dilakukan. 


\section{KESIMPULAN DAN SARAN}

\section{Kesimpulan}

Berdasarkan hasil penelitian mengenai Analisis Penerapan Economic Order Quantity (EOQ) di PG Madukismo Bantul, dapat diambil kesimpulan bahwa tahun 2013-2015 secara berturut-turut jumlah pemesanan tebu berdasarkan kebijakan PG Madukismo yaitu sebesar 29.377 kuintal dengan frekuensi 192 kali, 30.328.46 kuintal dengan frekuensi 168 kali, dan 31.883,06 kuintal dengan frekuensi 142 kali. Sedangkan berdasarkan perhitungan pemesanan tebu berdasarkan metode Economic Order Quantity (EOQ) tahun 2013 sebanyak 52.916,47 kuintal dengan frekuensi pemesanan 107 kali, tahun 2014 sebanyak 45.980,57 kuintal dengan frekuensi 111 kali, dan tahun 2015 sebanyak 49.135,20 kuintal dengan frekuensi 92 kali.

\section{Saran}

Sebaiknya PG Madukismo memperhitungkan Economic Order Quantity (EOQ), agar target produksi dapat terpenuhi dan keberlanjutan proses produksi dapat terjaga. Economic Order Quantity (EOQ) dapat dilaksanakan dengan menambah jumlah tebu setiap kali pesan dan mengurangi frekuensi pemesanan, sehingga total biaya pemesanan per musim giling lebih hemat.

\section{DAFTAR PUSTAKA}

Akindipe, O.S. 2014. The Role of Raw Material Management in Production Operations. International Journal of Managing Value and Supply Chains (IJMVSC). 5(3), 37-44.

Andari, B. 2016. The Importance of Raw Materials Inventory Supervision for Production Process. JARES. 1(1), 53-60.

Baroto, T. 2002. Perencanaan dan Pengendalian Produksi. Jakarta: Ghalia Indonesia.

Ernawati, L., \& Erma, E. 2013. Analisis Faktor Produktivitas Gula Nasional dan Pengaruhnya terhadap Harga Gula Domestik dan Permintaan Gula Impor dengan Menggunakan Sistem Dinamik. Jurnal Teknik Pomits. 1(1), 1-7.

Fadlallh, A.W. 2015. The Effect of Applying The Economic Order Quantity Model in The Field of Inventory. International Journal of Management (IJM). 6(4), 9-18.
Heizer, J., \& Barry, R. 2010. Operations Management: Manajemen Operasi (terjemahan) Buku 2, Edisi 9. Jakarta: Salemba Empat.

Kementerian Pertanian. 2015. Rencana Strategis Kementerian Pertanian tahun 2015-2019. Kementerian Pertanian Republik Indonesia. Jakarta.

Oktavia, E. 2014. Analisis Proses Kerja dalam Efisiensi Produksi di PTPN VII Unit Usaha Bungamayang (Skripsi S1). Bogor: Institut Pertanian Bogor. Tidak diterbitkan.

Rizaldi, D. 2004. Profil Tebu. Online: http://www.kppbumn.depkeu.go.id.

Ulfah, D.M. 2015. Skripsi: Pengaruh Penggunaan Jenis Gula terhadap Kualitas Kue Kembang Goyang Tepung Kacang Hijau. Universitas Negeri Semarang. Semarang.

Yolanda, Y. 2012. Analisis Pengendalian Persediaan Bahan Baku di Pabrik Gula Gondang Baru Kabupaten Klaten. Surakarta: Universitas Sebelas Maret. Tidak diterbitkan. 